\title{
APPLICATION OF BUTTERWORTH HIGH PASS FILTER AS AN APPROXIMATION OF WOOD ANDERSON SEISMOMETER FREQUENCY RESPONSE TO EARTHQUAKE SIGNAL RECORDING
}

\author{
Hamidatul Husna Matondang ${ }^{1}$, Endra Joelianto ${ }^{2}$, Sri Widiyantoro ${ }^{3}$ \\ ${ }^{1}$ BMKG, Jakarta, Indonesia, hamidatul.husna@bmkg.go.id \\ ${ }^{2}$ ITB, Bandung, Indonesia, ejoel@tf.itb.ac.id \\ ${ }^{3}$ ITB, Bandung, Indonesia, sriwid@geoph.itb.ac.id
}

\begin{abstract}
:
The method for generating maximum amplitude and signal to noise ratio values by using second order high pass Butterworth filter on local seismic magnitude scale calculations is proposed. The test data are signals from local earthquake that have been occurred in Sunda Strait on April 8th 2012. Based on the experimental results, a $8 \mathrm{~Hz}$ cutoff frequency and a gain of 2200 of second order Butterworth high pass filter as an approach to simulating the frequency response of Wood Anderson seismometer can provide maximum amplitude value, SNR, and the magnitude better than simulated Wood Anderson frequency response.
\end{abstract}

Keywords: High Pass Butterworth Filter; Wood Anderson Seismometer; Frequency Response Simulation; Instrument Correction

\section{INTRODUCTION}

Initially, the calculation of the local seismic magnitude scale was based on the calculation of the magnitude scale obtained from Wood Anderson's seismometer recordings. However, the Wood Anderson seismometer is a short period instrument that has analog recording, in which, the analog recording speed on paper is limited. This resulted in an earthquake recording on the recording station that was close to the location of the earthquake experiencing clipping. Therefore, recording earthquake signals from the Wood Anderson seismometer is no longer used in the calculation of local magnitude scales. Thus, the study of local magnitude has been shifted to the use of digital recording. In order to produce digital recordings as if coming from a Wood Anderson seismometer, the digital recordings are processed to simulate the Wood Anderson seismometer frequency response. The recording of the Wood Anderson frequency response simulation provides more accurate data from the original instrument, because there is no clipping on earthquake recordings [1]. However, in practice, the Butterworth filter application is still used to eliminate microseismic noise [2].

Considerable research has been done on simulating seismometer responses. Among them, designing a simulation of the frequency response of Wood Anderson seismometer from recursive filters with differential equations has been considered in [3]. The seismometer frequency response is considered as a second order high pass filter. If the filter is applied to an earthquake signal, the $2^{\text {nd }}$ order Butterworth high pass filter with a cutoff frequency of $2 \mathrm{~Hz}$ can approximate the local magnitude in 0.1 magnitude units [1]. The seismometer frequency response approach can also be obtained from a $5^{\text {th }}$ order Butterworth low pass filter cascaded with a $3^{\text {rd }}$ order Butterworth high pass filter [4]. These filters are used to correct short period and broadband seismometer responses. Pole and zero determination was provided for recursive filters used as a correction for seismometer instruments [5].

Different from previous studies, this paper tests earthquake signals using a second order Butterworth high pass filter with a cutoff frequency of 0.1 to $12 \mathrm{~Hz}$. The test data used in this paper are local earthquake signals and noise signals recorded by four earthquake recording stations. The Do the authors mean to correct short period and broadband seismometer responses recording stations are Cigelis Jawa Indonesia (CGJI), Lembang (LEM), Cisompet (CISI) and Karang Pucung Jawa Indonesia (KPJI). Local earthquake recorded signals used are the ones related to the earthquake that have occurred in the Sunda Strait on $8^{\text {th }}$ April 2012 at 08: 06: 47.1 am UTC +07.00 with a strength of 4.6 magnitudes, at coordinates longitude 105.859998 and latitude -6.94 with depth of $100 \mathrm{~km}$. While noisy signals were taken in the morning at 03.00 am UTC+07.00, noon at $12.00 \mathrm{pm} \mathrm{UTC}+07.00$ and at night at $10.00 \mathrm{pm}$ $\mathrm{UTC}+07.00[6]$. 
From the test results, the gain value and cut off frequency of the filter are configured considering the recorded data characteristic. The filter is then applied to the signal. The results of the filter application are expected to produce higher amplitude and signal to noise ratio (SNR) values than the simulated Wood Anderson's seismometer frequency response. The Butterworth filtered results are used as an approach to simulate earthquake recordings that would be obtained from a typical frequency response of a Wood Anderson's seismometer.

\section{PROPOSED METHODOLOGY}

The design is based on the similarity of responses between the Butterworth high pass filter and the Wood Anderson seismometer which is a second order system [7]. The filter is applied to earthquake signals that have been used for local seismic magnitude scale calculations. From the filtered signal, the maximum amplitude is obtained in the $\mathrm{S}$ signal phase and signal to noise ratio (SNR).

For comparison, the maximum amplitude and SNR of filtered earthquake signals are compared with the maximum amplitude and SNR of the earthquake signal on a simulated Wood Anderson seismogram. The research flow chart is shown in Figure 1.

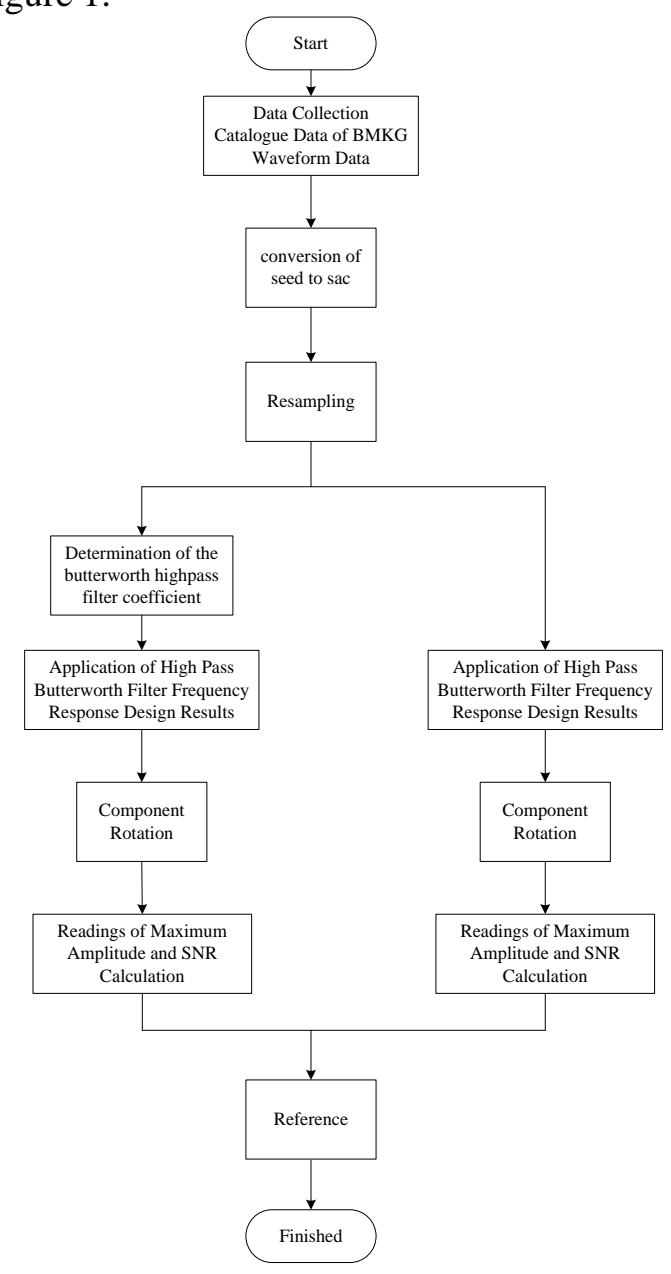

Figure 1: Flowchart of the Method

\section{ANALYSIS}

The results of the Butterworth filter test applied to BMKG data show an almost similar amplitude value for each earthquake recording station. The average maximum amplitude value for the four recording stations is $24,000,000 \mathrm{~nm}$, produced by the Butterworth filter with a gain of 3000 and a cutoff frequency of $0.1 \mathrm{~Hz}$. While the minimum amplitude is obtained from the gain with a value of 1000 and the cut-off frequency around $0.1 \mathrm{~Hz}$. See Figure 2.

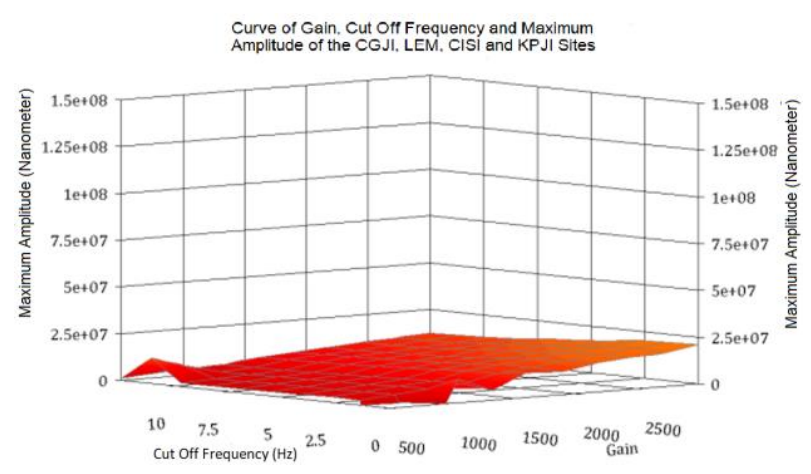

Figure 2: Cut off frequency, gain and maximum amplitude curves

It is also known that the frequency response of second order Butterworth Filter with gains of 2000, 2200, and 2300 have similarities with frequency response of Wood Anderson's Seismometer. However, the second-order Butterworth filter frequency response with a gain of 2200 and an $8 \mathrm{~Hz}$ cut-off frequency that is close to the maximum amplitude of Wood Anderson's seismometer.

The second-order Butterworth filter frequency response with a gain of 1000 has a magnitude smaller than the magnitude generated by the Wood Anderson seismometer. Whereas the second order Butterworth filter frequency response with a gain of 3000 has a magnitude greater than the seismic magnitude generated by the Wood Anderson seismometer. See Figure 3.

Table 1: Signal to noise ratio of Wood Anderson Seismometer and Butterworth Filter Simulated

\begin{tabular}{|l|c|c|c|c|c|c|}
\hline \multirow{4}{*}{ Station } & \multicolumn{3}{|c|}{ Simulated Wood } & \multicolumn{3}{c|}{ Butterworth Filtered } \\
\cline { 2 - 7 } & $3: 00$ & $12: 00$ & $22: 00$ & $3: 00$ & $12: 00$ & $22: 00$ \\
& Anderson & PM & PM & AM & PM & PM \\
& $(\%)$ & $(\%)$ & $(\%)$ & $(\%)$ & $(\%)$ & $(\%)$ \\
\hline CGJI & 6,7 & 3,9 & 1,8 & 5,1 & 6,2 & 6,6 \\
\hline LEM & 4,9 & 1,5 & 1,1 & $-1,3$ & $-1,3$ & 1,3 \\
\hline CISI & 2,1 & 1,4 & 4,1 & 4,6 & 3,7 & 5,2 \\
\hline KPJI & $-9,8$ & $-7,8$ & 2,9 & 3,0 & 2,8 & 3,1 \\
\hline
\end{tabular}

The largest maximum amplitude value of each recording station is obtained from the Butterworth filter simulation results, while the results from the 
Wood Anderson seismometer frequency response simulation have lower values. In calculating the signal to noise ratio values, the Butterworth filter frequency response simulation gives an increase in signal to noise ratio values at each recording station, but at the LEM and KPJI recording stations SNR decreases in the morning. This is caused by noise due to human activities. At the KPJI station, the percentage of SNR values decreased in the signal from the Wood Anderson seismometer frequency response simulation results. Meanwhile, the signal from the simulation results using the Butterworth filter is increased. However, this does not affect the results of local magnitude calculations. Simulation of Butterworth filter frequency response produces local magnitude values close to the seismic magnitude value released by BMKG of 4.6 [8]. While the local magnitude value is generated by Wood Anderson's frequency response seismometer simulation is 4.5 . It can also be seen that the local magnitude of the signal from the Butterworth filter simulation results has a more consistent value.
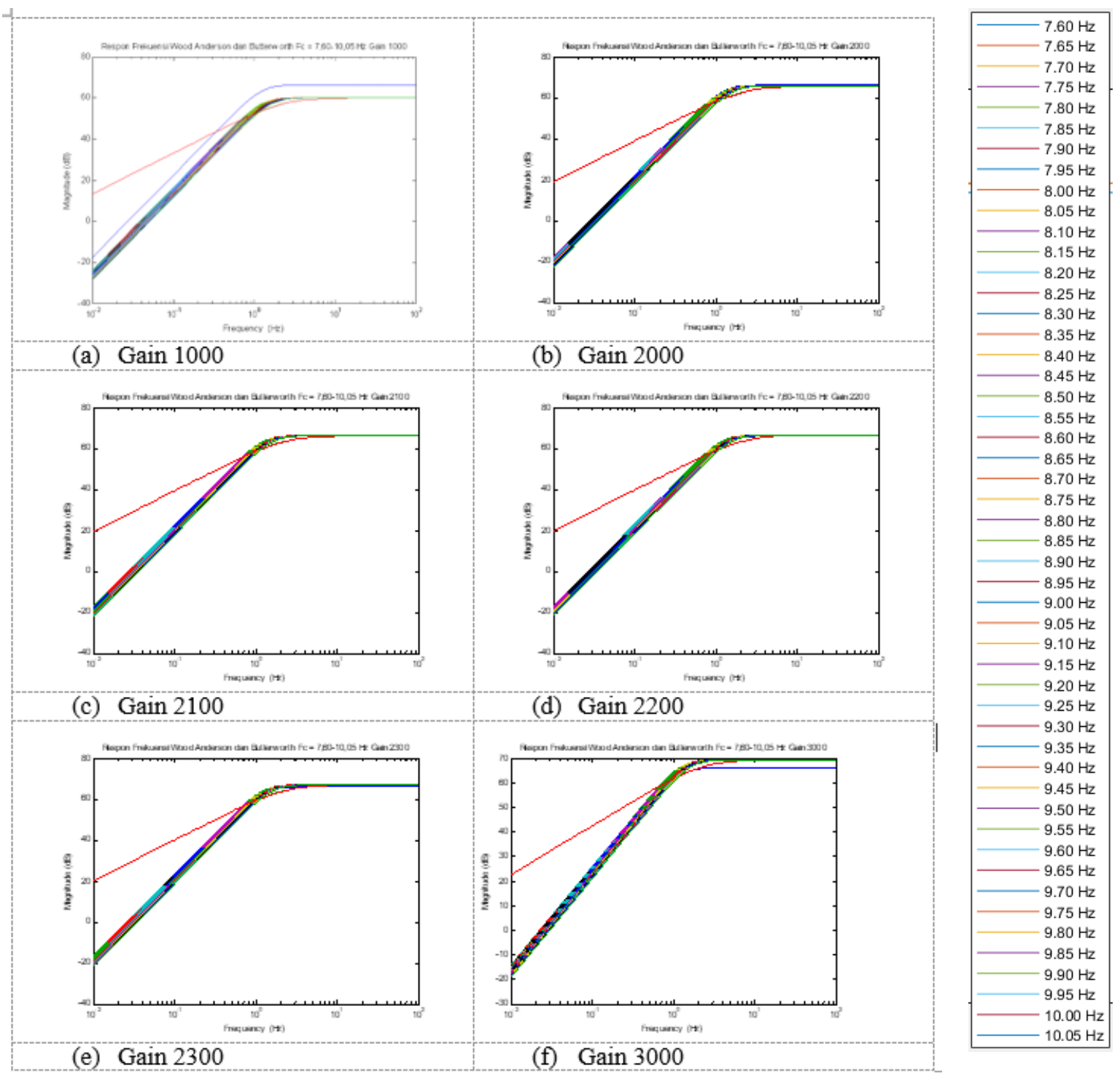

Figure 3: Comparison of Wood Anderson seismometer frequency response with Butterworth Filter cut off frequencies 7 to $9 \mathrm{~Hz}$

\section{SUMMARY}

In the paper, an earthquake signal processing algorithm was designed so that the signal was presented in physical displacement units. The second-order Butterworth filter with a gain of 2200 and a cut off frequency of $8 \mathrm{~Hz}$ had a maximum amplitude value and a higher SNR than the Wood Anderson seismometer. Hence, the Butterworth filter can be used as a Wood Anderson seismometer approach.

This research has the opportunity to be further developed so that it can be applied to the calculation of earthquake magnitude. However, it is necessary to calculate the local magnitude more accurately. In addition, it is necessary to have a greater number of observation stations. 


\section{REFERENCES}

[1] Havskov. J, and Ottemoler. L, "Routine Data Processing in Earthquake Seismology", Springer, pp. 14-160, 2010.

[2] Ottemoller. L, and Sargeant. S.T, "A Local Magnitude Scale $\mathrm{M}_{\mathrm{L}}$ for the United Kingdom", Bulletin of the Seismological Society of America, vol 103, pp. 2884-2893, 2013.

[3] Kanamori. H, Maechling. P, and Hauksson. E, "Continuous Monitoring of Ground-Motion Parameters", Bulletin of the Seismological Society of America, vol. 89, pp. 311-316, 1999.
[4] Haney, M.M, Power, J, West, M, and Michaels. P, "Causal Instrument Corrections for Short Period and Broadband Seismometers", Seismological Research Letters, vol. 83, pp. 834-845, 2012.

[5] Anderson. J. F, Lees. J. M, "Instruments Corrections by Time-Domain Deconvolution", Seismological Research Letters, vol. 85, pp. 197-201, 2014.

[6] http://202.90.198.92/arclink/query?sesskey

[7] Hutton. L.K, and Boore. D.M, "The $\mathrm{M}_{\mathrm{L}}$ Scale in Southern California", Bulletin of the Seismological Society of America, vol. 77, pp. 2074-2094, 1987.

[8] http://172.19.3.51 